\title{
Contextos e intertextualidades. Una incursión conceptual en el arte peruano contemporáneo
}

\section{CONTEXTS AND INTERCULTURALITIES. A CONCEPTUAL JOURNEY THROUGH CONTEMPORARY PERUVIAN ART}

Mihaela Radulescu de Barrio de Mendoza

Pontificia Universidad Católica del Perú

\section{RESUMEN}

La intertextualidad en el arte peruano contemporáneo es una constante cuyo valor va más allá del uso de un mecanismo de apropiación y resignificación de referentes culturales. Las redes que se establecen entre lo sagrado y lo profano, el pasado y el presente, lo local y lo global, por ejemplo, generan discursos a menudo polémicos y transgresores en torno a la identidad cultural del artista y de la cultura que representa. Plantea también interrogantes sobre el estatus del arte en el contexto actual y su enfoque epistemológico. En el Perú, son varios los artistas que desarrollan intertextualidades que pretenden incluir al público en escenarios e interacciones cuyos discursos apelan a su memoria para debilitar sus estereotipos y reconstruir representaciones nucleares para la configuración de la identidad. Analizar este fenómeno, su frecuencia e implicaciones, articula el arte a la historia y lo relaciona con la generación de saberes y lenguajes. Hay consecuencias en la percepción de la realidad y de su devenir: el arte desarrolla una vocación crítica desde lo cotidiano, apoderándose de signos para proponer una coenunciación activa y abastecida por los contenidos e íconos de la memoria colectiva de la comunidad.

PALABRAS CLAVE: intertextualidad, referente, enunciación, apropiación, resignificación, arte peruano

\section{ABSTRACT}

Intertextuality in contemporary Peruvian art is a constant whose value goes beyond the use of a mechanism of appropriation and re-signification of cultural references. The networks established between the sacred and the profane, the past and the present, the local and the global, for instance, generate often discourses controversial and transgressive around the cultural identity of the artist and the culture that he or she represents. It also raises questions about the status of art in the current context and its epistemological approach. In Peru, there are several artists who develop intertextualities that attempt to include the spectators in scenarios and interactions whose speeches appeal to their memory to undermine their stereotypes and reconstruct nuclear representations for the configuration of identity. Analyzing the frequency and implications of this phenomenon articulates art to history and relates it to the creation of knowledge and languages. There are consequences in the perception of reality and its future: art develops a critical vocation from the everyday, seizing signs to suggest an active co-enunciation, supplied by the contents and icons of the collective memory of the community.

KEYWORDS: intertextuality, referent, enunciation, appropriation, re-signification, Peruvian art 


\section{INTRODUCCIÓN}

La intertextualidad es una práctica enunciativa que se apropia de ficciones culturales instaladas en la memoria colectiva a través de la incorporación parcial o total de sus estructuras morfosintácticas. En el proceso se generan configuraciones discursivas y escenarios que producen sus propios contextos. Como estrategia creativa, la intertextualidad afirma un planteamiento semántico intencionalmente dialógico, del cual emergen no solo nuevos sentidos, sino también una voluntad transgresora en la que el deseo y la imaginación interactúan con la función crítica y el ejercicio del poder. En La parte maldita (1987), Bataille se refería a la potencia para explicar la desmesura que resulta de la transgresión. La potencia de la intertextualidad tiene como fuente una sublevación en contra del relato centralizador, al que reemplaza por una red de interacciones manifiestas; las estrategias figurativas resultantes dependen del proyecto narrativo de la práctica intertextual. La transgresión del régimen de la autoría es evidente: se asimila al otro en el mundo propio, sin borrar las huellas, reformulándolo, a la vez que se reformula la metanarrativa del autor. En el proceso, se desarrolla una ludificación de la práctica estructurante del artefacto cultural que sitúa en el centro de la semiosis el ars combinatoria y sus valores significantes, al mismo tiempo que motiva la inteligencia perceptiva del observador para indagar en el proceso creativo y sus referentes culturales. Comprender las implicancias de este proceso, incluyendo la desmesura percibida en las manifestaciones intertextuales del arte actual, requiere de un enfoque epistemológico transdisciplinario. El evento semiótico de la intertextualidad y la significación de los objetos intertextuales participan en una propuesta artística que recorre la diversidad contemporánea de los géneros del arte y que se ubica en la zona de los proyectos lúdico-utópicos (Semprini, 1992) de representación del insight estructural del autor, que pretende afirmar su identidad a través de un bricolaje de signos preexistentes (Floch, 1995).

La apropiación plantea un desfase entre el conjunto significante y el significado del artefacto asimilador. Este desfase funciona como matriz que provoca e implica al observador: "La seducción se basa en un excedente de significantes que no se puede reducir al significado" (Han, 2017, p. 92). La apropiación y la intertextualidad muestran su capacidad de hacer de la hibridez una instancia asumida e incluir en la heterogeneidad constitutiva de la imagen un espacio para la acción interpretativa del observador. El dialogismo se proyecta hacia la polifonía y la intertextualidad proporciona la matriz para esta expansión (Bajtín, 1991).

\section{LA INCORPORACIÓN DEL CONTEXTO}

El contexto y el cuerpo son los dos términos extremos de una relación en la cual las referencias traducen la afirmación pasional de la construcción de la identidad. Las representaciones son "expansiones internas que profundizan en el tema haciéndolo más 
denso, pero sin llegar a aumentarlo o a sobrepasar sus límites implícitos, pero siempre imperativos" (Connor, 2002, p. 18). La apropiación y la fusión híbrida se presentan como un proceso en el que intervienen por igual un formante estético y un formante cultural. Entre los dos generan no solo una intertextualidad cultural y una estética que se nutre de lo híbrido, sino también una red de articulación con un contexto al cual se le supone fuente e impulso del procedimiento. La hibridación y la transculturación del artefacto no anulan las huellas del contexto: estas se exponen en la enunciación enunciada y crean las condiciones para un metaespacio de interacción con la memoria del observador.

El cuerpo mestizo es el núcleo de la obra pop de Claudia Coca, que se inserta en el contexto peruano con una multiplicidad híbrida de representaciones de sí misma. Son representaciones intertextuales que se apropian de signos valóricos reconocidos por el contexto: la Virgen Inmaculada, personajes femeninos de Klimt y Lichtenstein, la Mujer Maravilla, Sarita Colonia. Los formantes estéticos y culturales ingresan en los autorretratos de la artista con una explícita y enfática intertextualidad; aportan a la expresión de la identidad individual la integración en el espacio peruano y universal, haciendo interactuar elementos de la historia de su vida con la cultura. Una primera contextualización procede de la autorreferencia: ella se retrata a sí misma en la variedad de imágenes de Mejorando la raza (2000), ¡Qué tal raza! (2002), Peruvian Beauty (exposición con Susana Torres, 2004), Plebeya (2005-2006), Globo pop (2007), Mestizaje sin paraíso (2009-2014), Mestiza (2014). Es un recurso que va más allá de la representación de sí misma como mestiza. "La saturación interna se convirtió en un principio discursivo", afirma Connor (2002, p. 18) al analizar los recursos de la cultura posmoderna. En las exposiciones mencionadas, el procedimiento de la hibridación produjo una saturación del universo emergente que podría ser interpretada como una restauración multirreferencial del proceso de autosignificación, a través del cual el cuerpo procesa y exhibe las huellas de sus vivencias culturales (Albuquerque, 2014). Hay una sublevación implícita en un autorretrato que necesita incorporar signos de reconocimiento y legitimación: la autorrepresentación de Claudia Coca advierte sobre la discriminación y la marginación del mestizo en la historia peruana hasta la actualidad. Esta es la segunda contextualización, que se entrelaza con la primera, para enfocar la configuración de los valores en la cultura poscolonial en América Latina. El primer efecto de la presión es la extensión, afirmaba Bataille (1987), y la intertextualidad manifiesta en la obra de Claudia Coca pone en marcha un discurso que expone las presiones del contexto (el racismo, la discriminación, la exclusión) desde la condición de mujer, con referencias a estereotipos, a mecanismos de exclusión, a hechos históricos como la esterilización forzada de los años noventa.

Los contextos incorporados por la intertextualidad son fuente de inferencias para el observador, quien se encuentra ante una estructura referencial provocativa, con un factor de extrañeza causado por el carácter híbrido de la imagen. El observador debe descubrir en la creación intertextual los significados del archivo traza (Foucault, 1979), 
es decir, de la transformación de la figura - forma en figura - imagen y deducir el punto de partida que determinó la apropiación de la otredad.

\section{LA APROPIACIÓN DE LA OTREDAD}

Claudia Coca escoge a la otra, reconocida por su belleza, entrega, valentía, sacrificio, protesta, para construirse a sí misma como proyecto en el cual convergen los valores utópicos y lúdicos de la autorrepresentación. Las mujeres que ingresaron desde el arte en sus autorretratos trajeron consigo el poder de actuar como representaciones iconográficas, aportando sus rasgos semánticos.

Héctor Acuña le da otro enfoque al tratamiento de la otra: el artista se apropia de representaciones icónicas culturales con valor arquetipal -la aristócrata, la prostituta, la guerrera, la japonesa, la drag queen- para interrogar sus significados. En sus exposiciones Fraumorphing: experimento de estética (2004), Gesto: simulacros de lo real (2005) y Frau Diamanda: Corpus Delicti (retrospectiva, 1999-2009), el procedimiento de la apropiación para la construcción del personaje Frau Diamanda pretendió borrar los límites entre el yo y la otredad, lo masculino y lo femenino, lo auténtico y lo escenificado, con ayuda de signos cuyos significados fueron sometidos a una praxis lúdica que los exponía, pero no los incorporaba en la construcción identitaria. Las construcciones intertextuales de Frau Diamanda no usaban la apropiación para hacer interactuar contextos, significados y valores, sino para generar sus propios significados y su propio contexto.

Hay un proyecto subyacente en este uso de la intertextualidad: construir la identidad desde la otredad. La otredad asumida es un proyecto expresivo, una presentificación (Husserl, 1992), que enfrenta el contexto sociocultural, su control y sus normas, con un cuerpo mutante capaz de reinventarse desde el insight afectivo. El formante estético provenía del drag, kitsch y camp; el formante cultural era el peruano, con sus presiones y categorías de identidad. El artista introdujo su existencia construida (la mutante Frau Diamanda) en espacios reales, llevando la metalepsis a extensiones progresivas (Genette, 2004): de la figura a la ficción y de la ficción al evento en la ciudad. Fue el recorrido de la Transversiva Post Andina Revolucionaria, inspirada en una fotografía de la Comisión de la Verdad y Reconciliación que mostraba a una mujer rondera empuñando un fusil.

Un recorrido similar ocurrió con la figura de la Virgen María, de la cual se apropió Giuseppe Campuzano para construirse como simulación, núcleo de un escenario nómada para su discurso de poder: el poder de reorganizar el universo de referentes culturales del contexto sociocultural peruano apelando a las realidades simbólicas existentes. El procedimiento fue explorado por Campuzano en varias de sus obras, por ejemplo, en el DNI rosado que exponía las dos instancias en contacto: el yo y la otra, travesti. El observador debía procesar una simulación que clausuraba el contexto real de la manifestación abriendo para la comunicación un espacio saturado de indicadores y teatralizado. 
Las performances de Héctor Acuña o de Giuseppe Campuzano apelaron a la modalidad teatral de la presencia (Landowski, 2007) y jugaron con la desmesura y el carácter mutante. Sus intertextualidades ubicaban en posición privilegiada los artefactos y signos de los cuales se han apropiado, para crear simulacros que descentraban al sujeto o mejor dicho lo transformaban en un metasujeto que desarrollaba un discurso sobre la sociedad y el ser humano desde el borde del contexto-escenario creado.

En la práctica, la apropiación de la otredad se hace incorporando en la práctica discursiva de la acción artística estructuras morfosintácticas que sean capaces de desencadenar la recordación y establecer redes semánticas y temáticas.

\section{APROPIACIONES MORFOSINTÁCTICAS}

En las exposiciones La migración de los santos (2008) y Así sea (2012), las instalaciones de Cristina Planas optaron por una intertextualidad de universos referenciales: el universo sagrado cristiano y el universo profano cotidiano de la gente. Usó elementos deícticos para facilitar la interpretación de las estructuras morfosintácticas que referían los dos universos desde un "entre" puesto en escena por las instalaciones y sus personajes. El "entre" fue esencial para generar un evento epifánico (Parret, 2008).

En esta intersección de lo sagrado y lo profano, las estructuras morfosintácticas se compusieron de manera híbrida. La migración de los santos se apropió de las representaciones religiosas para volverlas híbridas por el uso de objetos, vestimenta y medios de transporte. La composición de la instalación multiplicó las intertextualidades y la interacción de sus significados: en el altar del Señor de los Milagros, el Cristo Moreno estaba junto al dios de los temblores prehispánico, del friso del templo de Pachacamac. Al lado derecho, estaban san Martín y santa Rosa; a la izquierda se encontraba Sarita Colonia mirando a Cristo. Esta disposición propuso un escenario referencial metafórico que incluía la alteración de las representaciones: las espinas y los clavos de Cristo se reemplazaron por armas de fuego, Sarita Colonia vistió plástico transparente, santa Rosa tenía tatuajes, etcétera. La apropiación morfosintáctica intervino la iconografía, exigiendo por parte del observador la interpretación de las diferencias. En el nivel semántico hubo una negociación en el campo de la significación y del sistema de valores (Landowski, 2009), para la cual la apropiación de las estructuras morfosintácticas fue esencial.

La exposición Así sea desarrolló este enfoque interviniendo la regularización cultural de los rituales cristianos con un concepto de auto sacramental de la vida y de la muerte. Las intertextualidades se basaron en una selección morfológica de signos apropiados e intervenidos, inmersos en una composición propia, un frame que recogía los miedos del ser humano en un escenario paradigmático donde lo sagrado y lo profano se fusionaban. 


\section{LA GENERACIÓN DE SENTIDO EN LA INTERTEXTUALIDAD}

La intertextualidad interviene en la generación de sentido en por lo menos dos niveles: la acción significante de la construcción morfosintáctica apropiada para desarrollar construcciones semánticas híbridas; y la intersubjetividad que define la relación del autor y del observador, un "estado de encuentro" (Bourriaud, 2006) que funciona como acto colaborativo de generación de la significación. La conversión del artefacto fuente en el artefacto meta introduce la otredad como elemento flexible, objeto de posibles transcreaciones gracias a su potencial expresivo (Deleuze y Guattari, 1991, p. 157). La intertextualidad que se establece entre los dos artefactos, con su estructura referencial compleja que invita a lecturas dialógicas e interculturales, ofrece a la intersubjetividad un transobjeto y al observador una praxis colaborativa.

Las performances de Elena Tejada escenificaron el contexto nacional de los noventa apelando a signos y personajes cotidianos a los que incluyó en construcciones significantes que apuntaban a problemáticas históricas y sociales que el público reconocía y en las cuales se implicaba directamente. La intersubjetividad se desarrolló en un estado de encuentro afectivo, con indicadores morfológicos que tejían redes temáticas para la narrativa de sus obras. En Recuerdo (1998), performance realizada en el patio de la Facultad de Letras de la Universidad Nacional Mayor de San Marcos, la artista se arrastró en una bolsa negra de plástico por el piso, desde un símbolo pintado de escarapela a otro, gritando los nombres de los estudiantes desaparecidos de La Cantuta. Las escarapelas definían un recorrido en tiempo y espacio en la historia del país y funcionaron como referencias culturales para la experiencia del resurgimiento del hecho histórico (García Canclini, 2010). La Bomba y la bataclana en la danza del vientre (1999) o Burping Wonder Woman (2006), performances que alteran figuras de la cultura popular peruana (mujer de cabaret bailando en la primera) y norteamericana (la Mujer Maravilla eructando en la segunda), apelaron a personajes culturales reales o ficticios que podían ser reconocidos, junto con sus significados, por sus referentes nacionales e internacionales. En los dos casos, la intersubjetividad operó al margen de los paradigmas gracias a un détournement situacionista (Brea, 2002), sorprendiendo al observador y liberando de estereotipos a los personajes apropiados. En las tres performances, se desarrolla un discurso que pretende hacer cambios en la situación de recepción.

La generación de sentido desde la intertextualidad puede hacer funcionar discursos que apelan, argumentan y orientan su construcción hacia cambios contextuales: es el caso del Artículo 6 de Lucía Cuba, un conjunto de prendas-relatos de las esterilizaciones forzadas en el ámbito andino indígena del Perú en los años noventa. El proyecto registró los acontecimientos pasados a través de inscripciones en los textiles de las prendas: textos provenientes de los testimonios de las víctimas, que funcionan como trazas de la memoria. 
Cuando el discurso enfoca la problemática de la identidad cultural, la intertextualidad aporta su propia diversidad en la construcción de las interacciones. Para Ana de Orbegoso, las representaciones icónicas de la Virgen María fueron el punto de partida para producir imágenes híbridas de lo sagrado femenino en el espacio peruano. El proyecto creó una intertextualidad entre retratos de la Virgen de la pintura cusqueña y fotografías contemporáneas de mujeres y niños de los Andes, apelando al mismo tiempo a una intertextualidad conceptual con la tradición del sincretismo colonial y las procesiones religiosas. La composición heterogénea intervino en la creación de los personajes y de los escenarios, reales o simbólicos, de las doce obras que recorrieron el país en estandartes impresos y se instalaron en vallas urbanas, además de presentarse en galerías. La apropiación de signos y el ars combinatoria se centraron en el poder del acto creativo basado en la afirmación de lo femenino, desde el espacio local, con una intertextualidad simbólica de elementos sagrados y profanos. En las Vírgenes urbanas, la intertextualidad muestra signos del pasado histórico del Perú (Machu Picchu, catedrales coloniales, calles republicanas), el niño o los niños en los brazos de la Virgen, los angelitos niños de la calle, el bordado andino, las danzas de la sierra y de la costa, la bandera peruana, paisajes andinos.

Ampliando el territorio de las referencias intertextuales, Jorge Miyagui optó en sus pinturas por dejar a la vista las resistencias de los elementos morfológicos diversos ante una posible fusión, aunque comparten la presencia corporal recurrente que alude a las interacciones humanas. La diversidad es evidente en una composición descentrada, en la cual conviven sin integrarse cohesivamente elementos icónicos que emergen de la cultura popular y de la cultura mediática. Extraídos del contexto fuente, estos elementos intervienen en la generación de sentido por su semántica y por su participación en la hibridez constitutiva de las composiciones.

\section{CONCLUSIONES}

“Jugamos con la idea de representación", escribía Parsons (2002, p. 202). La intertextualidad lo hace reaccionando ante una sociedad sobrecargada de tensiones, deteriorada social y afectivamente (Han, 2012), con un proyecto de artífice que maneja una estructura polifónica para interrogar, deconstruir y reconstruir, resignificar desde la diversidad y la pluralidad. Los cambios registrados en la construcción de los discursos artísticos y en la fenomenología de la autoría son algunas de las consecuencias de su uso extensivo. La identidad es abordada desde el poder hacer del autor, que explora la relación entre la memoria individual y la memoria colectiva, con la voluntad de cambiar paradigmas e influir en el observador. La intertextualidad y sus modalidades generativas pueden ser interpretadas como una nueva práctica de la identidad que expone su preferencia por la presencia, el resultado manifiesto de las apropiaciones y referencias integradas en 
la construcción meta. No obstante, la intertextualidad activa interacciones que superan límites de tiempo y espacio, creando universos nucleares que integran fragmentos culturales en redes semánticas. Al exponer sus fuentes, muestra su matriz interdialógica y su capacidad de extensión semántica, ofreciendo al observador un mapa hipertextual de navegación cultural y una práctica colaborativa de generación de sentido. El autor afirma su rol e identidad en la selección y combinación estratégica de los signos, cumpliendo su rol de actante de la cultura desde el enfoque particular que asigna a la autorreferencialización, proceso que internaliza el querer, el saber, el poder y el hacer en un único planteamiento enunciativo.

\section{REFERENCIAS}

Albuquerque, I. R. de (2014). 0 corpo como soporte privilegiado de ornamento. Estudio, 5(9), 94-102.

Bajtín, M. (1991). Estética y teoría de la novela. Madrid: Taurus.

Bataille, G. (1987). La parte maldita. Barcelona: Editorial Icaria.

Bourriaud, N. (2006). Estética relacional. Buenos Aires: Adriana Hidalgo, editora.

Brea, J. L. (2002). La era postmedia. Acción comunicativa, prácticas (post)artísticas y dispositivos neomediales. Salamanca: CASA.

Connor, S. (2002). Cultura postmoderna. Introducción a las teorías de la contemporaneidad. Madrid: Akal.

Deleuze, G., y Guattari, F. (1991). Qu'est-ce que la philosophie? París: Minuit.

Floch, J.-M. (1995). Identités visuelles. París: PUF.

García Canclini, N. (2010). La sociedad sin relato. Antropología y estética de la inminencia. Buenos Aires: Katz Editores.

Genette, G. (2004) Metalepsis. De la figura a la ficción. Buenos Aires: Fondo de Cultura Económica.

Han, B.-C. (2012). La sociedad del cansancio. Barcelona: Herder Editorial.

Han, B.-C. (2017). La expulsión de lo distinto. Barcelona: Herder Editorial.

Husserl, E. (1992). Ideas relativas a una fenomenología pura y a una filosofía fenomenológica. Ciudad de México: Fondo de Cultura Económica.

Landowski, E. (2007). Presencias del otro. Lima: Universidad de Lima, Fondo Editorial.

Landowski, E. (2009). Interacciones arriesgadas. Lima: Universidad de Lima, Fondo Editorial. 
Parret, H. (2008). Epifanías de la presencia. Ensayos semio-estéticos. Lima: Universidad de Lima, Fondo Editorial.

Parsons, M. (2002). Cómo entendemos el arte. Barcelona: Paidós.

Semprini, A. (1992). El marketing de la marca. Una aproximación semiótica. Ciudad de México: Paidós. 